\title{
O NÃO RECONHECIMENTO DA FAMÍLIA POLIAFETIVA PELO ESTADO BRASILEIRO: UM ESTUDO SOBRE AS ESTRUTURAS DE PODER
}

\author{
Lorena Araújo Matos* \\ Thiago Augusto Galeão de Azevedo**
}

\section{RESUMO}

O presente estudo tem como finalidade observar a possível interferência do Estado nas relações privadas, mais especificamente, nas relações poliamorosas. Dessa forma, no primeiro momento destaca-se a constitucionalização do Direito Civil, dando uma interpretação conforme a Constituição Federal de 1988. No segundo momento trata-se-à da deslegitimação das relações poliafetivas, questionando o porquê de ainda haver tanto entreve ao reconhecimento dessas relações a família.

Palavras-chave: Direito de Família; Família poliamorosa; Estado; Relações privadas; Poder.

\section{THE FAILURE TO RECOGNIZE THE POLYAFETIVE FAMILY BY THE BRAZILIAN STATE: A STUDY ON POWER STRUCTURES}

\begin{abstract}
The present study aims to observe the possible interference of the State in private relations, more specifically, in polyamorous relations. Thus, in the first moment, the constitutionalization of Civil Law stands out, giving an interpretation according to the Federal Constitution of 1988. In the second moment, it is about the delegitimization of poly-affective relationships, questioning why there is still so much obstacle to the recognition of these family relations.
\end{abstract}

Keywords: Family Law; Polyamorous family; State; Private relations; Power.

\section{INTRODUÇÃ̃O}

O presente artigo tem como como objetivo analisar a interferência do Estado nas relações privadas, mais especificamente, nas relações poliafetivas, assim como questionar até que ponto preceitos religiosos e morais interferem na busca pelo reconhecimento dessas relações na sociedade.

Ressalta-se que nos últimos anos o Direito de Família vem vivenciando um relevante processo evolutivo. Com a vigência da Constituição de 1988, a família passa a incorporar um significado social ratificado pela preocupação do constituinte em lhe garantir proteção incidente sob todas as suas formas de manifestação. A família na sociedade pós-moderna

\footnotetext{
*Mestra em Direito Constitucional. Especialista em Direito Homoafetivo e de Gênero. Professora Universitária. Advogada. SHCES, Q. 605, BL. A, ap.203, CEP: 70655-650. E-mail: 1.maatos@ gmail.com.

**Pós-doutorando em Direito pela Universidade de Brasília. Doutor em Direito pela Universidade de Brasília. Professor da Universidade Federal do Mato Grosso. Advogado. Valdir Rabelo, 485, ap. 2021, CEP: 76600-011 E-mail: thiagogaleao@hotmail.com
} 
sofreu um alargamento em seu conceito, passando a ser entendida como um instrumento de realização da personalidade e da dignidade de seus componentes.

Atualmente os indivíduos buscam relacionamentos em que a afetividade é o princípio basilar na construção de uma família, portanto, a monogamia não é princípio determinante para a formação familiar.

O poliamorismo é uma prática antiga, entretanto, ainda assim, é repleta de discussões de cunho social, cultural, moral e até religioso. As mudanças ocorridas na sociedade e nas relações são relevantes para discussões na ciência do Direito e, portanto, extremamente relevante à análise do Estado, na figura do Judiciário, na configuração e regulamentação das relações poliafetivas.

As normas jurídicas necessitam acompanhar as evoluções ocorridas na sociedade, principalmente, no que diz respeito à configuração de novas formas de família, sabe-se que o conceito familiar já foi totalmente reformulado, pois, atualmente a afetividade é vínculo necessário para formar qualquer relacionamento.

Uma pesquisa acadêmica que tenha como enfoque a não-monogamia e o poliamorismo se mostra relevante, sobretudo, por se relacionar ao reconhecimento jurídico de organizações sociais posicionadas à margem da proteção normativa, garantindo direitos fundamentais a indivíduos que não seguem o padrão relacional estabelecido pela sociedade.

Para tanto, tem-se como objetivo geral de pesquisa analisar as estruturas de poder inerentes à sociedade que alicerçam o não reconhecimento da União Poliafetiva como Família. Para que o referido objetivo possa ser concretizado, inicialmente, analisa-se o fenômeno da Constitucionalização do Direito Civil e a valorização do afeto para fins conceituais da Família.

Em seguida, por meio de uma leitura filosófica, analisa-se a deslegitimidade da família poliamorosa, a partir da ideia de relações de poder sobre o corpo, sobre o sexo, propiciadoras de uma ordem social, que está pautada na monogamia, como um elemento moralista e controlador de vidas.

2 O FENÔMENO DA CONSTITUCIONALIZAÇÃO DO DIREITO CIVIL E A VALORIZAÇAO DO AFETO: UMA ANÁLISE PRINCIPIOLÓGICA 
Compatível com o objetivo proposto para a presente seção, entende-se fundamental, inicialmente, analisar o fenômeno da Constitucionalização do Direito Civil, isto porque o Direito de Família, ramo do Direito Civil no qual o caso está majoritariamente situado, não está mais ligado à sua concepção tradicional.

Concepção tradicional esta nitidamente influenciada pelo Código de Napoleão, séc. XIX, que era pensado a partir da concepção de autonomia do Direito Civil, das relações privadas, que estariam isoladas da intervenção do Estado, do Poder Público. Sobre o Direito Civil Tradicional, destaca-se o sustentado por Cardoso (2016, p.3):

\begin{abstract}
A formação do Direito Civil tradicional brasileiro foi influenciada pelo paradigma moderno e sua busca incessante por determinação. Escondido atrás do método das ciências duras e com foco na segurança, fez da clareza, coerência e completude seu mapa de aplicação. Logo, ignorou uma série de questões referentes aos seres humanos envolvidos, em cumprimento das normas preestabelecidas e às vezes, pela opção ideológica que escolhia o discurso que entenderia qual norma seria considerada preestabelecida. De fato, a realidade social codificadora em 1916 esteve completamente afastada da concretude e fática que a suportaria.
\end{abstract}

Um Direito Civil autônomo que pode ser vislumbrado, claramente, no Código Civil de 1916, documento este essencialmente patriarcal, liberal e patrimonialista. Marcado pela absoluta autonomia da vontade dos indivíduos. Os institutos fundamentais do Direito Civil, como contrato, propriedade e família, estavam tutelados tão somente no referido código, que se dizia o responsável exclusivamente por sua tutela, devido à citada autonomia do Direito Civil, a sua autossuficiência (VENOSA, 2015).

Todavia, o Direito de Família não deve mais ser analisado à luz de tal concepção tradicional, uma vez que com a vigência da Constituição de 1988, muito bem definida pelo termo "Constituição Cidadã", e do Código Civil de 2002, inúmeros princípios e normas marcadas por valores solidários passaram a permear o Direito Civil.

Trata-se de uma transição paradigmática valorativa, visto que no panorama do Direito Civil Tradicional se dava prevalência ao ter, por isso à propriedade e ao que estava consubstanciado em contrato; com a incidência dos citados princípios e normas, o ser passou a assumir um papel de protagonista, prevalecendo valores como dignidade da pessoa humana e solidariedade.

No que concerne ao princípio da dignidade da pessoa humana, pode-se relacionálo à proteção constitucional dada à família não constituída através do casamento (art. 226, §3 $\mathrm{CF}$ ), assim como à família monoparental (artigo $226, \S 4^{\circ} \mathrm{CF}$ ), à liberdade de escolha quanto a 
estrutura familiar, desde que à luz do princípio da paternidade responsável e à luz da proteção contra a violência doméstica no âmbito familiar, protegendo os seus integrantes (artigo 226, $\S$ $8^{\circ} \mathrm{CF}$ ). Assim, a dignidade da pessoa humana influencia em várias esferas da proteção dos direitos próprios ao instituto da família (GONÇALVES, 2011).

A Constituição Federal de 1988, nitidamente, representa um marco para o Direito Civil, uma vez que aquela assume institutos que se diziam exclusivos das relações privadas, do Direito Civil, como propriedade, família e contratos. Assim, o Direito Civil passa a ser permeado por normas e princípios constitucionais. O texto constitucional passou a demarcar os limites da autonomia privada, da propriedade, do controle de bens, da proteção do núcleo familiar.

Há, portanto, a constitucionalização do Direito Civil, um Direito Civil Constitucional. A propriedade, até então elemento que tinha um papel fundamental no Código Civil de 1916, assume um papel secundário, cedendo espaço para a dignidade da pessoa humana (VENOSA, 2015).

Neste novo panorama, destacam-se dois princípios de suma importância na CF/88, trata-se do princípio da igualdade, este entendido em sua concepção substancial ( $\operatorname{art} .5^{\circ} \mathrm{CF}$ ) e o princípio da solidariedade social (previsto no art. $3^{\circ}$, I, da CF). Dois dos principais princípios que irradiam as relações privadas, inclusive, as relações familiares.

No âmbito do Direito de Família, a citada transição paradigmática se faz evidente quando analisado o art. 226 da $\mathrm{CF} / 88$, onde fica consubstanciado, principalmente, um valor: a inclusão. Família não é mais aquela advinda, exclusivamente, do casamento. Incluem-se neste conceito outras formações, como as formadas através do afeto. Neste sentido, destaca-se o que preleciona Cristiano Farias e Nelson Rosenvald (2016, p. 73, grifo do autor):

\begin{abstract}
Em última análise, é possível afirmar: todo e qualquer núcleo familiar merece especial proteção do Estado, a partir da cláusula geral de inclusão constitucional. Equivale a dizer: todas as entidades formadas por pessoas humanas que estão vinculadas pelo laço afetivo, tendendo à permanência, estão tuteladas juridicamente pelo Direito das Famílias, independentemente de celebração de casamento. É o que vem se denominando família eudemonista, isto é, tendente à felicidade individual de seus membros, a partir da convivência, permitindo que cada pessoa se realize, pessoal e profissionalmente, convertendo-se em seres socialmente úteis, não mais se confinando ao estreito espaço da sua própria família.
\end{abstract}

A partir do citado excerto, pode-se destacar que a valorização do afeto nas relações familiares está nitidamente relacionada ao fenômeno da Constitucionalização do Direito Civil. Ao ponto em quese deva promover a inclusão no âmbito familiar, 
reconhecendo-se formas de vida, laços de afeto, mesmo que estes não se encaixem no padrão do casamento.

O princípio da afetividade, este como um produto do fenômeno de constitucionalização aqui analisado, apesar de não possuir previsão expressa na Constituição Federal, possui fundamento constitucional, com base nas noções de dignidade da pessoa humana (art. $1^{\circ}$, III, CF/1988), de solidariedade social (art. $3^{\circ}, \mathrm{I}, \mathrm{CF} / 1988$ ) e de igualdade entre os filhos (art. $5^{\circ}$, caput, e $227, \S 6^{\circ}$, da $\mathrm{CF} / 1988$ ), todos princípios constitucionais (TARTUCE, 2017).

Diante do contexto alcançado, permeado por noções como solidariedade, dignidade e igualdade, tornou-se insuficiente ignorar a qualidade das relações familiares em prol de um simples laço genético. Explica-se. Com a valorização da dignidade da pessoa humana, torna-se inadequado considerar as relações familiares apenas em seu caráter objetivo, biológico. As relações entre indivíduos em uma determinada sociedade, claramente, é mais complexa de que um simples resultado de exame de DNA, que atesta a paternidade, por exemplo.

Assim, passou-se a considerar a qualidade das relações sociais, entre elas as familiares, para fins de efeitos jurídicos, uma vez que é na qualidade da relação contraída entre sujeitos que valores como dignidade e solidariedade podem ser auferidos, como respeitados ou não.

A consideração do afeto nas relações familiares exerceu um grande impacto na formação familiar, uma vez que o conceito de família passou por substanciais transformações, influenciando diretamente na criação de um segundo princípio, o princípio da pluralidade das entidades familiares.

Trata-se de uma transição paradigmática ocorrida no seio do Direito de Família, que estava assentado no matrimônio, ao ponto em que a família advinha do casamento, exclusivamente. Com o advento da CF/1988, expandiu-se o conceito de família para relações que não estivessem pautadas no matrimônio, à luz do art. 226 da CF/1988, passando a ter proteção não mais tão somente a família advinda do casamento, mas qualquer outro tipo de expressão afetiva, como a união estável e a família monoparental. (FARIAS, ROSENVALD, 2016).

A família é objeto de uma nítida transição, deixa de ser compreendida tão somente como um núcleo econômico e reprodutivo, e passa a ser encarada como uma manifestação de 
afeto e apoio mútuo. Surgem, de forma consequencial, novos arranjos familiares, à luz da sobreposição da dignidade da pessoa humana sobre o patrimônio, do afeto sobre o casamento.

Sobre a temática, vale analisar o que Lôbo (2010, p.64) preleciona:

\begin{abstract}
A família recuperou a função que, por certo, esteve nas suas origens mais remotas: a de grupo unido por desejos e laços afetivos, em comunhão de vida. O princípio jurídico da afetividade faz despontar a igualdade entre irmãos biológicos e adotivos e o respeito a seus direitos fundamentais, além do forte sentimento de solidariedade recíproca, que não pode ser perturbada pelo prevalecimento de interesses patrimoniais. É o salto, à frente, da pessoa humana nas relações familiares.
\end{abstract}

O autor destaca a relevância do princípio jurídico da afetividade, este como potencial garantidor dos direitos fundamentais dos indivíduos, através da eliminação de desigualdades pautadas em critérios ilegítimos, fulcrados em interesses patrimoniais. Seria através do princípio em análise, que o instituto da família consegue, finalmente, recuperar as suas origens, que estão baseadas na união por sentimentos, afetividade e não apenas por laços consanguíneos.

Ademais, é cediço que o princípio da afetividade é reconhecido também pela jurisprudência pátria como elemento legitimador de efeitos jurídicos às famílias estruturadas no afeto, sublimando conceitos conservadores sobre o instituto da família, como o de que esta é fundada no casamento com fins de procriação.

É neste novo panorama valorativo que ganha destaque e reconhecimento a paternidade socioafetiva, em outros termos, o vínculo de paternidade criado a partir do afeto, descartando-se a ideia de que este vínculo só poderia advir de laços consanguíneos. Permitese, assim, uma abertura do conceito de família.

O conceito de família que perdurou por séculos, foi pautado no patriarcado, no qual a figura masculina prevalecia em detrimento da figura feminina, a mulher tida como submissa e incapaz só tinha utilidade para procriar e ser dona de casa, não tinha autonomia de escolhas de sua própria vida, sendo pertencente primeiro ao pai e depois ao marido.

Vale ressaltar que o direito privado por diversos momentos foi pautado por preceitos conservadores, ressalta-se a obra de Caenegem em "Uma introdução histórica ao direito privado", na qual destaca o espírito nitidamente conservador do Code de 1804, demonstrando o respeito aos direitos de família e de propriedade como base da ordem social.

O autor acima citado destaca que esse espírito do Code de 1804 enfatiza o papel indispensável exercido pela religião em todas as sociedades civilizadas, assim como ressalta o 
segundo pilar do Code que é a família, cuja característica principal era a submissão ao poder do marido e do pai.

Nesse contexto de submissão e de não aceitação a esse papel da mulher, que os movimentos feministas, segundo o autor Rafael da Silva Santiago (2014) em dissertação de mestrado publicado pela Universidade de Brasília, trouxeram diversas críticas ao casamento, fazendo alusão à submissão da mulher ao marido, proporcionando o surgimento de ideais que se fazem como base do poliamor, como o carinho, o afeto, a atenção entre os membros de uma mesma família.

Nesse contexto, o movimento feminista difundiu pesadas críticas ao casamento, qualificando-o como mecanismo de institucionalização da mulher como propriedade do homem, dando margem ao surgimento de valores inseridos no poliamor, como o carinho, a intimidade, a honestidade, a igualdade, a não-exclusividade e a autonomia relacional (SANTIAGO, 2014).

Segundo o autor acima, citando Haritaworn, Lin e Klesse, a cultura homossexual, mais especificamente a do gênero masculino, desenvolveu relacionamentos sexuais e íntimos pautados pela não monogamia, bem como os bissexuais que desenvolveram uma vivência de relacionamentos íntimos com pessoas de gêneros diferentes.

Observa-se que os fenômenos pautados na não-monogamia, a exemplo do poliamor, tem como fundamento principal a ideologia de libertação sexual, pois, por vezes o que é certo para uma parcela da sociedade para outros não é condizente com o modo de viver e manter seus relacionamentos sexuais e íntimos.

Destaca-se que o poliamor trata de relação afetiva íntima entre mais de duas pessoas, que, de forma transparente e gozando da sua autonomia da vontade, exercem seu direito de se relacionarem afetiva e sexualmente, com o intuito duradouro. São infinitas as possíveis formas desses relacionamentos sexuais-afetivos entre os adeptos, que podem ser definidos por regras consensuais e mutáveis (RAMALHO NETO, 2015).

O poliamor diferencia-se de outras formas de não-monogamia, tais como o swing, e as relações abertas, nas quais não há o intuito de se constituir uma união estável com mais de duas pessoas. Há, no poliamor, honestidade e boa-fé entre os envolvidos, que visam gozar de todos os efeitos legais de uma família. É essencial que se faça a presente distinção para o aprofundamento da questão. 
As relações poliafetivas, por vezes, são incompreendidas por falta de conhecimento, pois essas relações têm como base a honestidade e boa-fé, preceitos que nem sempre são encontrados nas relações ditas como "normais" ou a "regra" da sociedade, ou seja, relações monogâmicas.

Deodato, em artigo publicado de 2015, citando Regina Beatriz Tavares da Silva (2012, on-line), dispõe que as relações poliafetivas, também conhecidas como poliamor, "São relações interpessoais amorosas de natureza poligâmica, em que se defende a possibilidade de relações íntimas e duradouras com mais de um parceiro simultaneamente". Ademais, citando Rolf Madaleno, aduz que:

Esta é a família poliafetiva, integrada por mais de duas pessoas que convivem em interação afetiva dispensada da exigência cultural de uma relação de exclusividade apenas entre um homem e uma mulher vivendo um para o outro, mas sim de mais pessoas vivendo todos sem as correntes de uma vida conjugal convencional. É o poliamor na busca do justo equilíbrio, que não identifica infiéis quando homens e mulheres convivem abertamente relações afetivas envolvendo mais de duas pessoas.

Vale trazer entendimento do Supremo Tribunal Federal que não trata especificamente de uniões poliafetivas objeto do presente ensaio. Apenas pacificou entendimento pela distinção entre companheira e concubina, esta relação totalmente distinta do poliamor, uma vez que protege a instituição familiar. É também reconhecida no Direito brasileiro a união estável, sendo que nesta há a relação afetiva apenas entre não mais que duas pessoas (RAMALHO NETO, 2015).

O conceito do poliamor é diferente do concubinato. Na realidade, poliafetividade são relações concomitantes, com a ciência e consentimento dos envolvidos, que procura ser estável. Pressupõe a honestidade e a transparência, enquanto essas premissas não estão necessariamente presentes no concubinato. Em relação ao gênero, que é outra forma de relacionamento, o Supremo já superou a questão da união entre pessoas do mesmo sexo, reconhecendo a proteção legal às uniões homossexuais (RAMALHO NETO, 2015).

\section{DESLEgITIMIDADE DAS ENTIDADES POLIAFETIVAS: RELAÇÕES DE PODER SOBRE O CORPO}

Realizada a análise civilista sobre o instituto jurídico que é objeto de análise do presente artigo, com fins de concretizar a resposta a problemática sugerida no presente artigo, 
passar-se-á para a análise filosófica sobre a temática. Inicialmente, tratar-se-á das formas de poder em Michel Foucault, para que em um momento posterior se possa relacioná-las com a lógica subversiva do reconhecimento e aplicação do instituto do Poliamor.

A teoria do citado filósofo é marcada por reflexões acerca de relações de poder, que incidem sobre inúmeros objetos. Em níveis de recorte metodológico e teórico, o presente artigo preocupar-se-á com a articulação do citado poder com as relações afetivas entre indivíduos, principalmente à luz da sua obra História da Sexualidade: vontade de saber (2014). No que concerne às relações de poder, quatro conceitos se destacam na teoria de Foucault, trata-se do Poder Soberano, Poder Disciplinar e Biopolítica das Populações, as duas últimas como elementos constituintes de uma nova era, a chamada era do Biopoder. Formas de poder desveladas por Foucault, condizentes à épocas diferentes, possuindo configurações próprias.

Brevemente, a primeira forma de poder, Poder Soberano, era exercida à luz de uma lógica de confisco, de extorsão, de riquezas, de bens e até mesmo de sangue. Um poder que apreende o tempo, os corpos e a vida dos súditos em prol do seu soberano. Eis um poder que tem em sua centralidade a morte. De acordo com Foucault, trata-se de um poder compatível com o Direito, exercido através da lei (FOUCAULT, 2014).

Entretanto, a partir da época clássica, o Ocidente foi alvo de uma profunda transformação na lógica de exercício do poder. O poder que tinha a morte em sua centralidade perdeu espaço para um poder centrado na vida, não mais exercido pela repressão, sendo marcado pela disseminação, pelo empreendedorismo. Ressalva-se que não houve aqui uma substituição de uma forma de poder por outro, mas apenas uma alteração no grau de incidência, tanto que o poder soberano passa a assumir o papel de complemento do poder positivo, que tem em sua centralidade a vida.

Trata-se de novos procedimentos de poder que, de acordo com Foucault (2014), não mais funcionam pelo direito, mas pela técnica, não mais pela lei, mas pela normalização. Ao invés do castigo, controle, gerenciamento de corpos e de vidas. Um novo mecanismo de poder, exercido de duas formas: Poder disciplinar e Biopolítica das Populações. O primeiro tem como seu objeto os corpos dos indivíduos, inserindo estes em escalas de produção. Uma lógica marcada pelo panoptismo, no sentido de um controle permanente sobre corpos.

Vigilância permanente sobre os indivíduos por alguém que exerce sobre eles um poder - mestre-escola, chefe de oficina, médico, psiquiatra, diretor de prisão - e que, enquanto exerce esse poder, tem a possibilidade tanto de vigiar quanto de construir, 
sobre aqueles que vigia, a respeito deles, um saber. [...] Tem-se, portanto, em oposição ao grande saber de inquérito, organizado no meio da Idade Média através da confiscação estatal da justiça, que consistia em obter instrumentos de reatualização de fatos através de testemunho, um novo saber, de tipo totalmente diferente, um saber de vigilância, de exame, organizado em torno da norma pelo controle dos indivíduos ao longo de sua existência. Esta é a base do poder, a forma de saber-poder que vai dar lugar não às grandes ciências de observação como no caso do inquérito, mas ao que chamamos ciências humanas: Psiquiatria, Psicologia, Sociologia etc. (Foucault, 2013, p. 89).

Com a incidência do Poder Disciplinar, Foucault (2013) destaca a instauração de um poder-saber, fundado em altos níveis de vigilância, estruturado para efetuar um gerenciamento, um controle da existência humana. Trata-se da construção de um saber articulado com a normalidade, no sentido de ditar o que deve ser considerado como normal e anormal.

A segunda forma de poder incidente sobre a vida, Biopolítica das Populações, por sua vez, não se exerce sobre corpos individuais, como no poder disciplinar, mas sobre o coletivo. Este passa a ser controlado em níveis biológicos, gerenciando, por exemplo, as taxas de natalidade, mortalidade, além do direcionamento populacional.

Estas duas formas de poder, que possuem a vida em sua centralidade, constituem a chamada era do Biopoder, que representa, na teoria foucaultiana, o período em que a vida passou a ocupar o mesmo espaço da política, sendo objeto de um controle por um mecanismo complexo de poder.

Esclarecidos os principais conceitos relativos às relações de poder na teoria de Foucault, passar-se-á a refletir sobre o objeto central da presente seção, qual seja: o instrumento por meio do qual estas formas de poder são exercidas, mais especificamente, a discussão sobre o papel do Direito em relação à incidência do poder.

Conforme já ressaltado anteriormente, Foucault (2014) sustenta que o poder soberano seria tipicamente exercido pela lei. E mais, que o novo mecanismo de poder, que tem a vida em sua centralidade, não seria exercido pelo Direito, e sim pela técnica. Uma lógica de poder que não seria comportada pelo jurídico como instrumento de controle, conforme sustenta o filósofo Miroslav Milovic, em sua obra Política e Metafísica (2017).

Indaga-se: estaria o Direito alheio às relações de poder incidentes sobre a vida? A partir de uma interpretação literal da obra de Michel Foucault, poderia se chegar à resposta de que o Direito seria um instrumento de poder exclusivo do Poder Soberano, da morte, não tendo qualquer relação com as relações de poder positivas, incidentes sobre a vida. Entretanto, 
considerando o que se pretende refletir e analisar com o presente artigo, não parece esta ser a melhor interpretação. Explica-se.

Parte-se de uma concepção não essencialista do Direito, concepção esta sustentada por François Ewald (1986), filósofo francês, assistente de Foucault na década de 1970. À luz de sua concepção sobre o Direito, este não existe enquanto essência, estando marcado diretamente por sua relação com a historicidade, o que é compatível com a obra de Michel Foucault. É a partir desta concepção, que Márcio Alves da Fonseca, em sua obra Michel Foucault e o Direito (2002), trata do Direito à luz de imagens na teoria foucaultiana. O citado filósofo brasileiro sustenta três imagens do Direito na teoria de Foucault: o Direito como Lei, o Direito normalizado-normalizador e o Direito novo. Imagens estas que são construídas a partir da relação do Direito com a norma.

A primeira imagem identificada por Fonseca (2002), Direito como Lei, está relacionada à já discutida posição do Direito em relação ao Poder Soberano, quando se discutiu que este era exercido, essencialmente, por meio da Lei, do Direito. Trata-se de uma concepção do Direito em que este assume o valor de sinônimo da Lei. Todavia, destaca-se que o Direito, na obra de Foucault, não possui esta valoração única, podendo-se identificar um outro conceito de Direito, no qual a norma não está em oposição, e sim em articulação com o mesmo. Trata-se do Direito normalizado-normalizador, no sentido de que este é objeto de uma normalização, e a partir do momento que é atravessado por esta, passa a normalizar, também.

O Direito, nesta segunda imagem destacada por Fonseca (2002), assume o papel de vetor de normalização. Eis um processo de transição, em que a lei gradativamente passa a funcionar como norma. Processo este que está associado ao novo mecanismo de poder destacado anteriormente, centrado na vida e não mais na morte. Nas palavras de Foucault (2014, p. 156-157, grifo nosso):

[...] Não quero dizer que a lei se apague ou que as instituições de justiça tendem a desaparecer; mas que a lei funciona cada vez mais como norma, e que a instituição judiciária se integra cada vez mais num contínuo de aparelhos (médicos, administrativos etc.) cujas funções são sobretudo reguladoras. [...] Por referência às sociedades que conhecemos até o século XVIII, nós entramos em uma fase de regressão jurídica; as Constituições escritas no mundo inteiro a partir da Revolução Francesa, os códigos redigidos e reformados, toda uma atividade legislativa permanente e ruidosa não devem iludir-nos: são formas que tornam aceitável um poder essencialmente normalizador. 
A partir de tais constatações, pode-se elucidar um comentário realizado em relação ao poder positivo ser exercido pela técnica e não mais pela lei. Propõe-se, a partir da teoria apresentada por Fonseca (2002), uma linha de interpretação. Não é que o Direito não esteja articulado com o novo mecanismo de poder incidente sobre a vida, não mais servindo como um de seus instrumentos; e sim que o Direito, na concepção de ser um sinônimo da lei, não mais comporta o citado poder, uma vez que este é complexo o bastante para ser exercido pela repressão legal. Pelo contrário, trata-se de um poder que funciona de forma positiva, empreendedora. Assim, deve-se ressaltar que não é o Direito que se apaga perante esse mecanismo de poder incidente sobre a vida, e sim a sua imagem que o conceitua como sinônimo da lei.

Trata-se de uma proposta de interpretação que permite articular o Direito, na obra de Foucault, como um objeto e um instrumento desse novo mecanismo de poder, que tem a vida em sua centralidade. Uma concepção do Direito em que este assume a posição de implicação com a norma. Eis uma interpretação condizente com o que Foucault (2014) sustenta acerca do saber, de que todo saber está atravessado por um poder, não existindo um saber alheio à normalização.

Frisa-se que é esta concepção do Direito, na obra de Foucault, que permite a reflexão proposta pelo presente artigo. Por isso se partiu desta, para que depois a análise se torne mais específica. É somente a partir da consideração da possibilidade do Direito ser irradiado e um instrumento irradiante de normalização, que se pode refletir sobre formas deste ser um instrumento de subversão, de emancipação em relação à mesma.

Em outras palavras, apenas a partir da análise da possibilidade do Direito estar articulado com o Poder, sendo objeto de normalização e instrumento desta, que se pode propor uma reflexão sobre o seu impacto no corpo, no âmbito do controle da liberdade dos indivíduos, especificamente a partir da utilização de identidades; que se pode pensar em um Direito Novo, livre de normalização.

À luz da teoria de Michel Foucault, pode-se identificar que a sociedade contemporânea está imersa em um campo de poder. Um poder que se transmuta, que se revigora diariamente. Um poder que se apresenta com faces diferentes cotidianamente. Uma lógica de poder empreendedora, que controla os nossos corpos, nossas vidas, nosso respirar, em aspectos coletivos e individuais. Trata-se do chamado Biopoder, já analisado na seção anterior. 
Eis o poder que possui como centro a vida. É a vida dos indivíduos que deve ser preservada, mesmo que para tanto seja necessário instaurar uma lógica de controle, de gerenciamento de vidas. Vidas que devem estar pautadas em padrões de normalidade, condenando-se aqueles que não seguem a linha da normalidade, sendo considerados desviantes. Produz-se a linha do normal, quem não segue esta linha é dotado de anormalidade, não devendo ter prestígio ou mesmo reconhecimento de sua forma de vida em sociedade.

À luz de Michel Foucault (2014), o sexo se tornou público, objeto do discurso. Precisava-se saber tudo sobre o mesmo, as posições sexuais dos casais, os seus sonhos eróticos. Tudo precisaria ser contado para aquele que receberia a confissão, o médico. Tratase de um controle social que filtra as relações sexuais dos casais, dos nubentes e de seus filhos (crianças e adolescentes), projetando-se um padrão de relação que seria considerada como normal e a única adequada - a relação entre um homem e uma mulher, sob o regime do casamento.

Esta lógica de controle buscava, inclusive, mapear as anormalidades, as condutas sexuais, afetivas, que seriam desviantes, fora da linha de normalidade, sendo ilegítimas. Nisto, a medicina, mais especificamente, a psiquiatria teve um papel determinante, categorizando indivíduos, assinalando perigos, anormalidades; seguidos da proposta de cura, de tratamento (FOUCAULT, 2014).

Pode-se relacionar esta lógica de poder, controladora e impositora de padrões, às relações que seriam legítimas a serem consideradas em sociedade. $\mathrm{O}$ afeto, neste contexto, não seria algo valorizado, até mesmo porque este é descartável em uma sociedade dominada por uma lógica de mercado, biopolítica econômica neoliberal, na qual o indivíduo que consegue ascender é aquele que se adequa à lógica de empresário de si próprio, na qual o indivíduo não deve parar para refletir sobre a sua vida, ou mesmo, importa-se com o seu próximo e sim produzir, porque tempo é dinheiro e a lei é enriquecer.

Deve-se atentar, assim, que relações fora do casamento não seriam legítimas e mais, casamento entre homens e mulheres. O que fugisse desses padrões seria considerado ilegítimo, indigno de reconhecimento. Na curva desviante estão as relações homoafetivas e as relações poliamorosas.

Esta lógica de poder excluir inúmeros modos de vida. Não se reconhece, por exemplo, as relações afetivas formadas em nível do chamado Poliamor. Trata-se de uma lógica de normalização que impõe como padrão a relação formada por um homem e uma 
mulher, não havendo espaço, legitimidade, para a cumulação de vínculos, mitigando-se o princípio da afetividade.

Em um contexto de poder no qual o afeto não seria valorizado, a linha de raciocínio que se pode sustentar é que o normal, o vínculo detentor de prestígio por uma lógica de poder controladora, é a relação formada por dois indivíduos, heterossexual. Esta seria a considerada normal, legítima e reconhecida para fins de efeitos jurídicos.

Poder-se-ia questionar: sob qual fundamento teórico se pode sustentar que a relação heterossexual, entre duas pessoas, seria a valorizada, a partir de uma perspectiva foucaultiana? No presente artigo, parte-se da concepção de que a sociedade contemporânea vive sob a égide de um poder que tem como agente de controle o mercado, a chamada biopolítica econômica neoliberal. Compatível a esta lógica está a ideia de mão-de-obra, precisa-se desta para sustentar o próprio sistema capitalista, logo nada mais razoável do que valorizar a relação heterossexual, formada por um homem e uma mulher. Estes seriam considerados os normais, os padrões, dos quais os vínculos afetivos, assim como qualquer tipo de relação que não tenha a procriação como uma possibilidade seria considerada desvalorizada, não detentora de legitimidade em nossa sociedade.

A própria Biopolítica reproduz uma lógica de poder, de controle de corpos em níveis coletivos. Entre as esferas de controle, destacadas por Foucault (2014), cita-se o controle de natalidade. Podendo-se atentar, assim, para uma lógica de instrumentalização dos laços consanguíneos, à luz da concepção de produção de mão-de-obra que seja compatível e controlável, refletindo as necessidades mercadológicas de cada sociedade.

É importante destacar, considerando o que foi apresentado no tópico anterior, que esta lógica de poder atravessa o Direito, por diversas vezes, uma vez que este é um exemplo de saber-poder na teoria de Michel Foucault. Trata-se de um objeto, e ao mesmo tempo, um vetor de poder, de normalização. Esse Direito normalizado-normalizador pode ser observado nas leis pátrias, principalmente, no âmbito do Direito de Família, que antes da Constituição de 1988 e do próprio fenômeno da Constitucionalização do Direito Civil estava pautado na valorização única do vínculo biológico, não se reconhecendo relações pautadas na socioafetividade.

Neste sentido, considerando o que foi discutido ao longo da presente pesquisa, pode-se sustentar que o reconhecimento das relações poliamorosas como entidades familiares funciona como um elemento contra majoritário, de subversão a uma espécie de poder, que 
promove o reconhecimento de modos de vida que não são classificados como normais, como padrões.

São modos de vidas desviantes que passam a existir juridicamente, passando a ter reconhecimento jurídico. Assim, defende-se que o reconhecimento do instituto do Poliamor é um instrumento de inclusão, de sensibilização a formas de vida, a laços sociais que transbordam a norma, que transcendem à lógica de normalidade construída por um poder que domina os nossos corpos, as nossas vidas.

Em 2012, foi veiculado pelos meios de comunicação o reconhecimento de união estável, através de escritura pública, entre um homem e duas mulheres, no município de TupãSP. A tabeliã argumentou que não havia vedação legal para a aludida lavratura e que era autorizada a isso pelos princípios constitucionais da igualdade, dignidade da pessoa humana e da liberdade para justificar a juridicidade de tal reconhecimento público (RAMALHO NETO 2015).

Nota-se que o argumento utilizado pela tabeliã vai além da literalidade da lei, ela faz uma interpretação em que resguardar os direitos individuais, a dignidade humana e a liberdade de formar uma família é mais importante do que priorizar a monogamia, a qual a sociedade preza tanto, mas não prioriza o principal: a liberdade de formar a família.

No exemplo acima, indivíduos conseguiram, por meio de escritura pública lavrada em cartório, que fosse reconhecida união estável entre um homem e duas mulheres. Conseguiram reconhecimento oficial de um direito de suas personalidades, contra o qual o Estado não deveria, prima facie, opor-se. Esse ato implica em diversos efeitos jurídicos sucessórios, pessoais, previdenciários, que não podem ser menosprezados pelos juristas (RAMALHO NETO, 2015).

Em que pese o referido reconhecimento, o Conselho Nacional de Justiça, CNJ, em 2018, decidiu pela impossibilidade de reconhecimento da união estável poliafetiva como uma entidade familiar, sob a base, entre outros argumentos, de que haveria uma imaturidade social da União Poliafetiva para que a mesma possa ser considerada Família. A monogamia como um elemento estrutural da sociedade.

PEDIDO DE PROVIDÊNCIAS. UNIÃO ESTÁVEL POLIAFETIVA. ENTIDADE FAMILIAR. RECONHECIMENTO. IMPOSSIBILDADE. FAMÍLIA. CATEGORIA SOCIOCULTURAL. IMATURIDADE SOCIAL DA UNIÃO POLIAFETIVA COMO FAMÍLIA. DECLARAÇÃO DE 
VONTADE. INAPTIDÃO PARA CRIAR ENTE SOCIAL. MONOGAMIA. ELEMENTO ESTRUTURAL DA SOCIEDADE. ESCRITURA PÚBLICA DECLARATÓRIA DE UNIÃO POLIAFETIVA. LAVRATURA. VEDAÇÃO. [...]

8. A sociedade brasileira não incorporou a "união poliafetiva" como forma de constituição de família, o que dificulta a concessão de status tão importante a essa modalidade de relacionamento, que ainda carece de maturação. Situações pontuais e casuísticas que ainda não foram submetidas ao necessário amadurecimento no seio da sociedade não possuem aptidão para ser reconhecidas como entidade familiar. (CNJ - PP - Pedido de Providências - Corregedoria - 0001459-08.2016.2.00.0000 - Rel. JOÃO OTÁVIO DE NORONHA - $48^{\mathrm{a}}$ Sessão Extraordinária - julgado em 26/06/2018).

Interessante observar na referida ementa a colocação do sujeito em níveis de generalização. Como relator projeta sobre a sociedade, de uma forma universal, a impossibilidade de a União Poliafetiva adquirir o status de inteligível. Mesmo que fosse verídico, qual seria a base para pensar que a maioria estaria correta sobre ceifar o reconhecimento de modos de vidas de terceiros? Em que medida seria adequado a ingerência do Estado sobre relações privadas, por meio de uma suposta sensação de que a sociedade não estaria pronta para o citado reconhecimento? E mais, qual a relação da vida privada da sociedade para com a proibição do reconhecimento do modo de vida alheio?

Nesse sentido, Maria Berenice Dias destaca:

O que nos une é uma imensa vontade de mostrar que o Direito das Famílias como prefiro chamar, precisa ser visto sob uma nova ótica, voltada muito mais ao resgate da cidadania dos seus membros. Há necessidade de uma postura diferenciada para tratar do mais humanos de todos os direitos, pois diz com o que o ser humano tem de mais precioso: seus afetos (2010).

Portanto, a decisão do CNJ de 2018 viola o direito de afeto do ser humano, família não é o que parcela da sociedade - ainda que majoritária - acredita que seja, vai além dos estereótipos, dos preconceitos.

A legislação que regula as relações familiares é a mais difícil de ser modificada. Projetos de lei que buscam regular situações novas que eclodem em uma sociedade mais livre e menos conservadora, enfrentam enorme resistência para serem aprovados. Há uma grande dificuldade em permitir que os fatos da vida recebam a chancela jurídica (DIAS, 2010).

Analisando o contexto legislativo e correlacionando com a decisão acima do CNJ, percebe-se a resistência em aprovar e modificar leis que versem sobre o Direito de Família, por conta de uma concepção extremamente conservadora e retrógrada, dessa forma, é 
evidente que não se cabe mais abarcar um único modelo familiar, apenas para não afetar a estrutura social conservadora, que insiste em não evoluir.

Sendo assim, em nome da manutenção do Estado, da preservação da sociedade, buscase manter a família, olvidando-se que esta é integrada por pessoas que entretêm relações marcadas pela desigualdade. Homens, mulheres e crianças ainda ocupam lugares definidos de forma hierarquizada (DIAS, 2010).

No artigo intitulado "As normas abertas e o método de ensino jurídico", de Roberto Freitas, o autor destaca que:

O ensino jurídico tradicional pressupõe o método dedutivo e a subsunção como categorias interpretativas primordiais. $\mathrm{O}$ aluno aprende o direito estatal, o direito positivado, encarando as normas como se fossem conceitos definíveis na forma de premissas maiores às quais se possam subsumir todos os fatos da vida social do homem. (FREITAS, 2013)

Dessa forma, fica evidente que ao tratar das relações poliamorosas muitos pensadores do Direito, sejam estudantes, advogados ou juízes passam a ter que enfrentar uma matéria que não é debatida ou refletida nas suas formações iniciais, pois ainda se prioriza o direito positivado, a leitura da lei, não priorizando a reflexão no ensino jurídico, as situações ocorridas no meio jurídico são, por vezes, complexas e, dessa forma, sempre será preciso exercitar a reflexão, atentar-se para o indivíduo enquanto sujeito de direitos e proteger sua dignidade humana.

Chegou o momento de retirar o véu da hipocrisia, da mentira e da falsidade e admitir que a família tradicional brasileira, por vezes, é a que mais esconde as mazelas e prejuízos emocionais e físicos para os indivíduos do seio familiar. Chegou o momento de legislar em prol do amor e do afeto.

\section{CONSIDERAÇÕES FINAIS}

O poliamor vai além de discutir a liberdade de escolha de cada ser humano, buscam-se mudanças de paradigmas na própria formação jurídica, o Direito e a própria reflexão dos juristas precisam evoluir para além da análise pura da lei.

As novas formas de famílias surgem para quebrar preconceitos e pré-julgamentos, demonstrando que nada é generalista ao ponto de ser adequado para todo e qualquer ser humano, a monogamia funciona para diversas relações afetivas, entretanto, há sim pessoas 
que não se adequam a monogamia e, portanto, podem e devem ir em busca do que é melhor para sua vida afetiva.

As famílias poliamorosas preenchem todos os pressupostos para configurar uma entidade familiar, portanto, a monogamia não se configura em um princípio do Direito, como sustentam algumas doutrinas e a jurisprudência do Superior Tribunal de Justiça, mas configura sim uma mera imposição social.

O Código Civil ao tratar de direitos inerentes à família ainda não regula questões como o direito sucessório, entretanto, é ilógico não resguardar direitos às famílias poliafetivas, deixando-as a margem de direitos, por isso é fundamental aceitar e proteger que há sim famílias diversas, com vontades diversas e indivíduos distintos que buscam acima de qualquer preceito legal, religioso e moral a sua felicidade e liberdade de escolha.

Não é preciso formulação de novas leis para proteger e reconhecer as famílias poliafetivas, a própria Constituição é o instrumento que fundamenta e reconhece a dignidade humana de todos os indivíduos, uma simples reinterpretação do artigo 226 da Constituição é capaz de transformar em reconhecimento milhares de famílias que almejam reconhecimento e respeito no meio jurídico e social e, de fato, é o que merecem: respeito e reconhecimento.

\section{REFERÊNCIAS BIBLIOGRÁFICAS}

BRASIL. Constituição (1988). Constituição da República Federativa do Brasil. Brasília, DF: Senado Federal, 1988.

CAENEGEM, R. C. van. Uma introdução histórica ao direito privado. $2^{\mathrm{a}}$ ed. Martins Fontes. 2000.

CARDOSO, Simone Tassinari. Notas sobre parentalidade biológica e socioafetiva: do direito civil moderno ao contemporâneo. Civilística. A. 5. N. 1. 2016.

DIAS, Maria Berenice. A família além dos mitos. Disponível em: http://www.berenicedias.com.br/discursos.php?codigo=298\&termobusca=\#anc. Acesso em 14 de abril de 2021.

EWALD, François. L’état providence. Paris: Grasset, 1986.

FARIAS, Cristiano Chaves de; ROSENVALD, Nelson. Curso de Direito Civil: Famílias. V.6. 8 ed. Salvador: JusPodivm, 2016.

FONSECA, Márcio Alves da. Michel Foucault e o Direito. São Paulo: Max Limonad, 2002. 
FOUCAULT, Michel. A Verdade e as Formas Jurídicas. Rio de Janeiro: Nau Editora, 2013.

FOUCAULT, Michel. História da sexualidade I: A vontade de saber. Trad. Maria Thereza da Costa Albuquerque e J. A. Guilhon Albuquerque. $1^{\text {a }}$ ed. Rio de Janeiro/ São Paulo: Paz \& Terra, 2014.

FREITAS FILHO, Roberto. As Normas Abertas e o Método do Ensino Jurídico. In: José Garcez Ghirardi e Marina Feferbaum. (Org.). Ensino do direito em debate : reflexões a partir do $1^{\circ}$ Seminário Ensino Jurídico e Formação Docente. 1ed. São Paulo: Direito VG, 2013, v. 1, p. 71-94.

LÔBO, Paulo. Direito Civil: famílias. $3^{\text {a }}$ ed. São Paulo: Saraiva, 2010.

MILOVIC, Miroslav. Política e Metafísica. São Paulo: Max Limonad. 2017.

RAMALHO NETO, Deodato José. A Possibilidade Do Poliamorismo Enquanto Direito Personalíssimo E A Ausência De Regulamentação No Direito Brasileiro. Artigo publicado pelo Conselho Nacional de Pesquisas e Pós-Graduação em Direito. 2015.

SANTIAGO, Rafael da Silva. O Mito da Monogamia à Luz do Direito CivilConstitucional: necessidade de uma proteção normativa às relações de poliamor. Dissertação apresentada ao Programa de Pós-Graduação em Direito da Universidade de Brasília (UNB). 2014. Disponível em: < http://repositorio.unb.br/bitstream/10482/16193/1/2014_RafaeldaSilvaSantiago.pdf>. Acesso em: 15 de dezembro de 2016.

TARTUCE, Flávio. Direito Civil: Direito de Família. V.5. 12 ed. Rio de Janeiro: Forense, 2017.

VENOSA, Sílvio de Salvo. Direito Civil: Parte Geral. V.1. 15 ed. São Paulo: Atlas, 2015. 